\title{
РЕГИОНАЛЬНАЯ МЕЖ УПРАВЛЕНЧЕСКАЯ КОМИССИЯ: ЛОКАЛЬНОЕ ПРОСТРАНСТВО ДЛЯ СОГЛАСОВАНИЯ И МЕЖФЕДЕРАЛЬНОЙ АРТИКУЛЯЦИИ?
}

\section{ОРИГИНАЛЬНАЯ СТАТЬЯ}

SANTOS, Nadja Romeiro dos ${ }^{1}$, COTA, Ana Lídia Soares²

SANTOS, Nadja Romeiro dos. COTA, Ana Lídia Soares. Региональная меж управленческая комиссия: локальное пространство для согласования и межфедеральной артикуляции? Revista Científica Multidisciplinar Núcleo do Conhecimento. Год 06, эд. 09, Vol. 03, с. 173-189. Сентябрь 2021 года. ISSN: 2448-0959, Ссылка доступа:

https://www.nucleodoconhecimento.com.br/технология-ru/меж-управленческаякомиссия, DOI: 10.32749/nucleodoconhecimento.com.br/ru/98474

\section{СВОДКА}

Региональная межведомственная комиссия (CIR) формирует пространство для согласия, формулирования, сотрудничества и укрепления региона здравоохранения. Цель этого исследования состояла в том, чтобы поразмышлять о нормативных механизмах, которые лежат в основе построения комиссии как места для консолидации регионального управления для смягчения межфедеральных конфликтов. Имея в качестве руководящего вопроса: каким образом региональные межправительственные комиссии предоставляют локальные пространства для согласования и межфедеративного обсуждения? Качественное исследование, основанное на документальных исследованиях, основанное на анализе резолюций

\footnotetext{
${ }^{1}$ Докторант магистерской программы в области общества, технологий и государственной политики. Университетский центр Tiradentes (UNIT).

2 Доктор педиатрической стоматологии, профессор курса стоматологии и аспирантуры по обществу, технологиям и государственной политике (UNIT / AL) Университетский центр Tiradentes.
}

RC: 98474

Доступно в: https://www.nucleodoconhecimento.com.br/технология-ru/меж- 
региональных комиссий по управлению Алагоас, соответствующих периоду с 2017 по 2019 год, с использованием Указа 7508/11 в качестве справочного стандарта. Результаты были разделены на четыре категории: региональное планирование здравоохранения; организация мероприятий и услуг здравоохранения: регион здоровья; Федерализм, CIR и фринансирование здравоохранения; управление и CIR: канал переговоров и принятия решений между муниципальными менеджерами и государством в рамках региона здравоохранения. Региональные межуправленческие комитеты проводят значительную работу по обсуждению региональной политики, являясь фрундаментальным инструментом для укрепления управления на территориях путем переговоров распределение и распределение ресурсов, необходимых для планирования, промежуточных соглашений и фринансирования здравоохранения, играющих важную роль для региональной системы здравоохранения Алагоас как демократического, политического и кооперативного пространства.

Ключевые слова: Управление здравоохранением, Единая система здравоохранения, Федерализм, Политика в области здравоохранения.

\section{1. ВСТУПЛЕНИЕ}

Политика Бразилии в области здравоохранения была разработана в соответствии со статьей 196 Федеральной конституции (CF/1988), основанной на мерах и услугах в области общественного здравоохранения, которые являются частью региональной и иерархической сети, представляющей собой единую систему (SUS), организованную в соответствии с различными руководящими принципами, включая децентрализацию, всесторонний уход и участие общин (статья 198) (BRASIL, 1988).

Крупным шагом вперед в этом смысле стало регулирование Органического закона о здравоохранении (Закон 8.080/90) фредеральным указом № 7,508,

$\mathrm{RC}: 98474$

Доступно в: https://www.nucleodoconhecimento.com.br/технология-ru/меж- 
опубликованным в июле 2011 года, в соответствии с которым нормативноправовая база, уплотняющая конституционные и правовые положения, связанные с реализацией основного права на здоровье в Бразилии, нодиты относительно децентрализации общественного здравоохранения, с организацией SUS, планированием действий в области здравоохранения и межфедеративной артикуляцией.

Одно из главных достижений относится к введению в действие SUS на региональной территории, от утверждения пространств согласия и обсуждения с целью определения правил совместного управления, называемых региональными межуправлением комиссиями (CIR), поскольку процесс децентрализации общественного здравоохранения, одна из конституционных предпосылок, усиливается с легитимацией региональных пространств согласия.

Этот политико-административный процесс SUS в Бразилии, победивший образец в Национальном учредительном собрании (1986-1988), был консектантом одного из главных требований Движения за санитарную реформу, построенного из-за различных критических замечаний к централизованной модели, действующей в то время в стране, выполненной в то время Национальным институтом медицинской помощи социального обеспечения (INAMPS).

Этот организационный принцип был также включен в другие установленные государственные стратегии, особенно в области здравоохранения, образования и социальной помощи, которые во взаимном согласовании структурируют основы государства социальной защиты.

Согласно Wagner (2006), децентрализация, как правило, приводит к автономии принятия решений в отношении здравоохранения для федеративных образований. Растущая фринансовая централизация государства наряду с продолжающимся осуществлением бюджетного регулирования штатов и

$\mathrm{RC}: 98474$

Доступно в: https://www.nucleodoconhecimento.com.br/технология-ru/межуправленческая-комиссия 
муниципалитетов и решающая роль в разработке политики привели к сочетанию централизации штатов с децентрализацией секторальной политики, которая в случае здравоохранения всегда зависела от федерального введения (VIANA et al, 2002).

Под регионом понимается непрерывное географическое пространство, сорормированное кластерами соседних муниципалитетов, определяемых из существования культурных, социальных и экономических идентичностей и других, с целью интеграции, организации, планирования и выполнения действий и услуг в области здравоохранения (BRASIL, 2011).

Именно в этих условиях CIR выделяются в качестве инструментов поддержки реализации политики в области здравоохранения в федеративных регионах. На практике они фрункционируют как примеры регионального управления сетями здравоохранения, действия которых имеют отношение к динамике регионализации, выявлению проблем, определению приоритетов и предложению решений для их организации, помогая в определении общих целей и в установлении логики, ориентированной на благосостояние населения и предоставление медицинских услуг.

Именно в контексте сохранения муниципального протагонизма и укрепления отношений взаимозависимости и санитарной совместной ответственности между государством и муниципальными образованиями возникает CIR, имеющий в качестве миссии управление Региональной политикой в области здравоохранения, основанное на знании эпидемиологической и социальноэкономической реальности соседних муниципалитетов.

Что касается штата Алагоас, то CIR координирует создание Региональной сети по оказанию помощи (RAR), обеспечивая доступ населения к медицинским услугам, регулирующим, контролирующим и оценивающим цели, установленные для муниципалитетов, включенных в их район.

$\mathrm{RC}: 98474$

Доступно в: https://www.nucleodoconhecimento.com.br/технология-ru/меж- 
Поэтому целью данной статьи является размышление о нормативных положениях, лежащих в основе построения CIR как пространств консолидации регионального управления, смягчающих межфедеративные конфрликты, анализе регионализации в SUS, стремлении проверить влияние межправительственного сотрудничества на укрепление этой стратегии. В поддержку предложенного анализа были рассмотрены теоретические ссылки по теме, начиная от обзора основ фредерализма, SUS в бразильской федеративной структуре и концепций децентрализации и регионализации, заканчивая обсуждением некоторых критических фракторов. С учетом вышеизложенных размышлений возник следующий вопрос: каким образом CIR обеспечивает локальные пространства согласия и межфедеративной артикуляции?

\section{2. МЕТОДОЛОГИЯ}

Это описательное и исследовательское исследование с качественным подходом, осуществляемое посредством тематического обзора и анализа содержания офрицальных документов $\mathrm{CIR} / \mathrm{AL}$, как пространства для согласования и межфедеративного артикуляции SUS, позволяющего агрегировать знания об изучаемом объекте, а также анализировать прогресс политики общественного здравоохранения от процесса регионализации (MINAYO, 2010).

Мы проанализировали резолюции, разработанные CIR, соответствующие периоду с 2017 по 2019 год, доступные для общественности на странице Официального вестника штата Алагоас (DOE / AL) http://www.imprensaoficial.com.br/diario-oficial, используя Указ 7.508/11 в качестве эталонного стандарта. Выводы были систематизированы в четыре аналитические категории, сгруппированные после прочтения документов, выводы которых расположены в таблице 1, то есть: планирование (категория 1); организация (категория 2); (Категория 3) и управление (Категория 4).

$\mathrm{RC}: 98474$

Доступно в: https://www.nucleodoconhecimento.com.br/технология-ru/меж- 


\section{3. ПОЛУЧЕННЫЕ РЕЗУЛЬТАТЫ}

Из в общей сложности 192 прочитанных резолюций была разработана аналитическая основа (таблица 1), в которой для руководства обсуждением были рассмотрены основные обсуждения в CIR и его соответствующее значение в качестве соответствующего содержания ранее избранных категорий.

Таблица I: Характеристика резолюций по категориям анализа за период 20172019 гг.

\begin{tabular}{|c|c|c|}
\hline Категория & $\begin{array}{l}\text { Чувство } \\
\text { обдумывания }\end{array}$ & Основные обсуждения \\
\hline \multirow[t]{5}{*}{ Планирование } & \multirow{5}{*}{$\begin{array}{l}\text { Стратегии } \\
\text { сотрудничества, } \\
\text { способствующие } \\
\text { соглашению, } \\
\text { обеспечивающие } \\
\text { доступ населения к } \\
\text { медицинским } \\
\text { услугам. } \\
\text { Стратегия, } \\
\text { благоприятствующая } \\
\text { качеству реализации } \\
\text { политики в области } \\
\text { здравоохранения. }\end{array}$} & 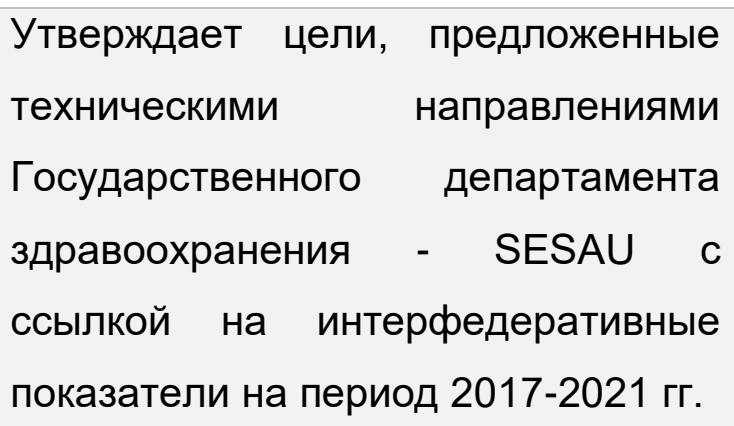 \\
\hline & & $\begin{array}{l}\text { Утверждает планирование } \\
\text { здравоохранения, здравоохранение } \\
\text { и межфедеративную артикуляцию }\end{array}$ \\
\hline & & $\begin{array}{l}\text { Утверждает Государственный план } \\
\text { гуманизации здравоохранения } \\
\text { штата Алагоас на четырехлетний } \\
2016 \text { - } 2019 \text { годы и Оперативный } \\
\text { план на } 2017 \text { год }\end{array}$ \\
\hline & & $\begin{array}{l}\text { Реактивные цели } \\
\text { интерфедеративных показателей. }\end{array}$ \\
\hline & & Внесены изменения В \\
\hline
\end{tabular}

RC: 98474

Доступно в: https://www.nucleodoconhecimento.com.br/технология-ru/меж- 


\begin{tabular}{|c|c|c|}
\hline & & $\begin{array}{l}\text { Государственный план Сети по } \\
\text { уходу за инвалидами в целях } \\
\text { введения } \\
\begin{array}{l}\text { стимулирования финансового } \\
\text { Министерства здравоохранения }\end{array}\end{array}$ \\
\hline & & $\begin{array}{l}\text { Утверждает план действий службы } \\
\text { в качестве справочника для } \\
\text { макрорегиона работоспособности }\end{array}$ \\
\hline Организация & Организация услуг, & Утверждает включение службы \\
\hline & $\begin{array}{l}\text { что способствует } \\
\text { укреплению сети } \\
\text { здравоохранения в } \\
\text { регионе. }\end{array}$ & $\begin{array}{lc}\text { Утверждает } & \text { Карту } \\
\text { лабораторных } & \text { справок } \\
\text { проведения } & \text { цитопатологических } \\
\text { тестов для скрининга на рак шейки } \\
\text { матки. }\end{array}$ \\
\hline & & $\begin{array}{l}\text { Утверждает Руководство } \\
\text { лечению вне дома - TFD Alagoas. }\end{array}$ \\
\hline & & $\begin{array}{l}\text { Одобряет создание коек оит в } \\
\text { рамках Сети по чрезвычайным } \\
\text { ситуациям и чрезвычайным } \\
\text { ситуациям (RUE) }\end{array}$ \\
\hline & & $\begin{array}{l}\text { Одобрено перераспределение } \\
\text { психиатрических коек в области } \\
\text { здравоохранения }\end{array}$ \\
\hline & & $\begin{array}{ll}\text { утверждает включение в состав } \\
\text { Отделения } \\
\text { уровень ІІІ }\end{array}$ \\
\hline & & $\begin{array}{l}\text { Утверждает внедрение } \quad \text { Блока } \\
\text { долгосрочного ухода - UСP }\end{array}$ \\
\hline & & Утверждена квалификация задних \\
\hline
\end{tabular}

RC: 98474

Доступно в: https://www.nucleodoconhecimento.com.br/технология-ru/меж- 


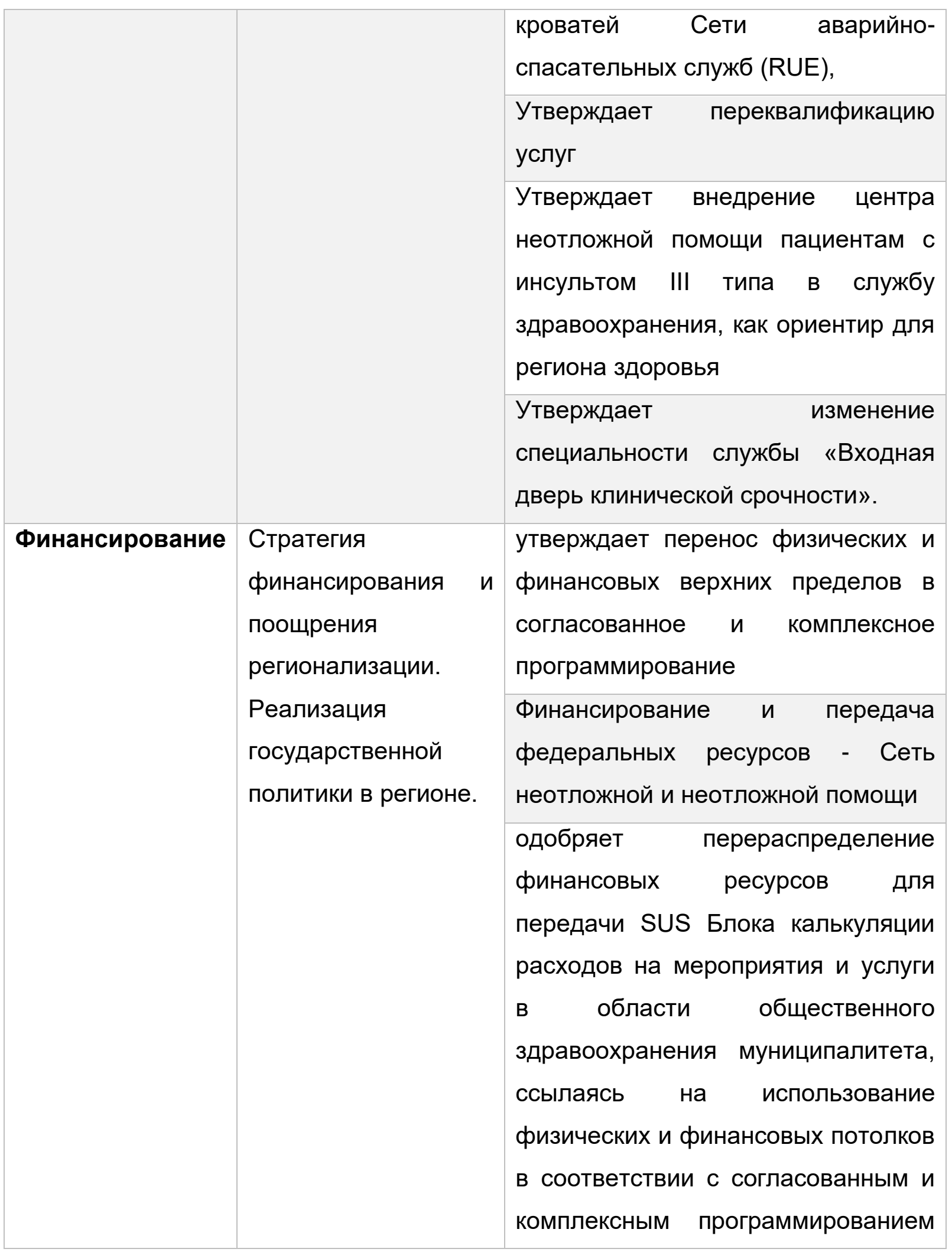

RC: 98474

Доступно в: https://www.nucleodoconhecimento.com.br/технология-ru/меж- 


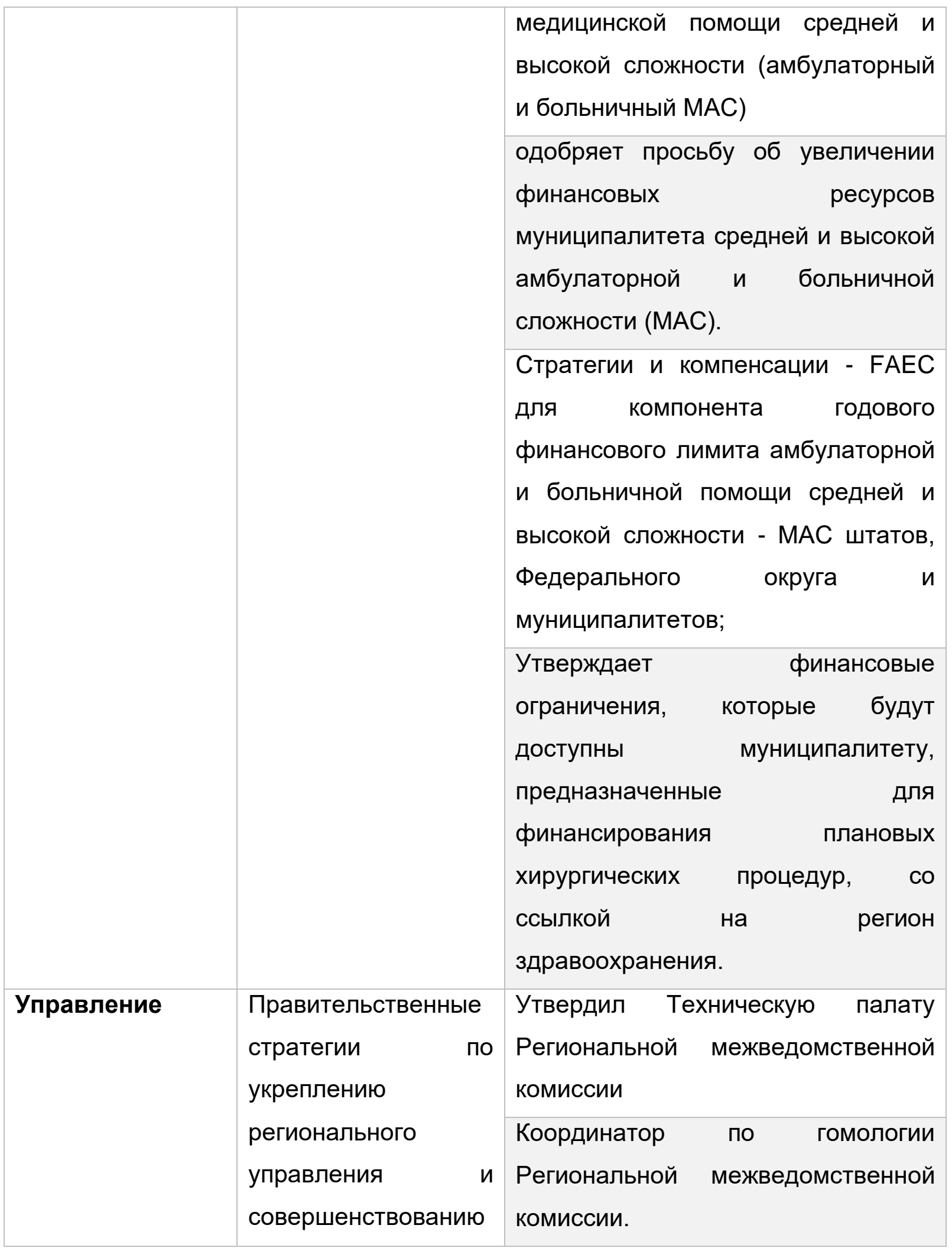

RC: 98474

Доступно в: https://www.nucleodoconhecimento.com.br/технология-ru/меж- 


коммуникационных
сетей,
способствующие
интегральности
федеративных
действий.
Поддержка
совместного
управления.

Источник: Собственное авторство, 2020

\section{4. ОБСУЖДЕНИЕ}

\section{1 РЕГИОНАЛЬНОЕ ПЛАНИРОВАНИЕ ЗДРАВООХРАНЕНИЯ}

Планирование является постоянным и динамичным процессом и должно также включать чрезвычайные ситуации, рассматриваемые в краткосрочной перспективе. В области здравоохранения планирование является компетенцией трех сфрер государственного управления и формирует основу для осуществления, мониторинга, оценки, контроля и управления системой здравоохранения, предполагая знание существующей реальности и инструментов, имеющихся и необходимых для достижения предлагаемых целей.

По мнению Santos (2017), отсутствие планирования наносит ущерб организации медицинских услуг, ослабляя сотрудничество и координацию политики регионализации. Так, В своей ст. 176 Федеральной конституции она определяет, что она является обязательным планированием для государственной власти и индуктором для частного сектора (BRASIL, 1988).

RC: 98474

Доступно в: https://www.nucleodoconhecimento.com.br/технология-ru/межуправленческая-комиссия 
Процесс регионализации здравоохранения позволяет распределять услуги в сети здравоохранения, с тем чтобы рассматривать все уровни здоровья в соответствии с потребностями отдельных лиц. Документы, проанализированные в этом исследовании, показали, что планирование стало важной повесткой дня в повестке дня обсуждения менеджеров в регионах здравоохранения.

Одним из следствий планирования является уточнение обязанностей трех сорер управления, определение предоставления услуг и управления ими и вклада фринансовых ресурсов. Таким образом, процесс планирования и составления бюджета должен быть неделимым. Таким образом, бюджетное программирование в области здравоохранения имеет важное значение как неотъемлемая часть и деталь планов здравоохранения (BRASIL, 2011).

По словам Duarte и других сотрудников (2018), организация планирования и бюджета SUS идет по восходящей, интегрированной, осуществляемой регионализированным образом, от признания проблем здравоохранения каждого муниципалитета, построенного через артикуляцию между автономными образованиями, с целью обеспечения качества жизни населения, через организацию медицинских услуг. На практике планирование и организация деятельности каждого уровня направления SUS будет осуществляться на подъеме, руководствуясь потребностями населения в области здравоохранения, посредством организации плана здравоохранения в каждой юрисдикции, где его фринансирование предусмотрено в бюджетном предложении (BRASIL, 1990).

Интегрированное региональное планирование устанавливает CIR в качестве пространства для фрормулирования, переговоров и согласования между подписавшими его субъектами, позволяя выявлять, определять приоритеты и согласовывать решения для организации региональной сети действий и услуг

$\mathrm{RC}: 98474$

Доступно в: https://www.nucleodoconhecimento.com.br/технология-ru/межуправленческая-комиссия 
интегрированного и резолютивного здравоохранения в соответствии с принципами SUS (BRASIL, 2011).

CIR имеет важное значение для консолидации политики в области общественного здравоохранения путем мониторинга Комплексного согласованного программирования в целях содействия построению нормативного проекта с определением потоков и протоколов с целью квалификации социального контроля и организации совместного управления на восходящем уровне, запланированного с определением фринансовых и административных ресурсов, способствующих регионализации (BRASIL, 2011).

Результаты документального анализа показывают, что CIR является пространством с потенциалом для развития институционального потенциала, регионального территориального планирования и координации, направленного на преодоление корпоративных интересов и создание местного самоуправления на основе совместного управления и демократизации межправительственных решений и сотрудничества.

\section{2 ОРГАНИЗАЦИЯ МЕРОПРИЯТИЙ И УСЛУГ В ОБЛАСТИ ЗДРАВООХРАНЕНИЯ: РЕГИОН ЗДОРОВЬЯ}

Анализ постановлений CIR показывает, что организация здравоохранения является постоянным «этапом» обсуждения в фредеративных сорерах, свидетельствующим о том, что сети здравоохранения являются направлением для работы по согласованию в рамках Межуправленических комиссий (BRASIL, 2011).

Организацию медицинского обслуживания следует рассматривать в регионах здравоохранения, которые представляют собой непрерывное географическое пространство, объединенное группой муниципалитетов, составляющее территориальную основу для планирования медицинского обслуживания,

$\mathrm{RC}: 98474$

Доступно в: https://www.nucleodoconhecimento.com.br/технология-ru/меж- 
которое является результатом совместного регионального фринансирования посредством предоставления услуг, направленных на управление в регионе, на основе сотрудничества между федеративными образованиями; должны содержать действия первичной медико-санитарной помощи, психосоциальной помощи, медицинского надзора, неотложной и неотложной помощи, специализированной амбулаторной и больничной помощи (BRASIL, 2011).

Для интеграции действий и услуг общественного здравоохранения в регионализованную сеть необходимо, чтобы фредеративные организации работали комплексно.

Такая совокупность услуг в регионе необходима для обеспечения интегральности медицинской помощи посредством потока справочных и контрссылок, и более крупный руководитель должен отвечать в регионе за услуги большей сложности, которые требуют масштаба и других административных и технологических компонентов, к которым могут получить доступ муниципалитеты других федеративных образований (ANDRADE; FRANCISCHETTI, 2019).

По мнению Santos (2017), сотрудничество между инстанциями соглашения на территории, как способ организации пространств работы SUS, является ключевым моментом, учитывая его санитарную, технологическую и финансовую уникальность, являющейся основополагающей в структурировании SUS. Без этого организационного формата система здравоохранения не смогла бы обеспечить всестороннюю, равноправную и децентрализованную помощь.

В качестве способа организации и интеграции этой сети услуг на территории подписавшие стороны берут на себя ответственность, установленную в Организационном договоре о государственных действиях (СОАР), с целью обеспечения действий и услуг в области здравоохранения на региональной и иерархической основе с определением исполнительной, бюджетной,

$\mathrm{RC}: 98474$

Доступно в: https://www.nucleodoconhecimento.com.br/технология-ru/меж- 
финансовой и контрольной оценки, определяемой между государствами, Муниципалитет и Союз, устанавливающие цели в области здравоохранения для калькуляции затрат и инвестиций, которые гарантируют полный уход за населением (BRASIL, 1990, 2010, 2011; SANTOS, 2017).

Решение квалифицировать здравоохранение и управление включает в себя технические, этические и культурные аспекты, с необходимостью соблюдения политического пакта о сотрудничестве между органами управления системой, выраженного «тонкой ассоциацией техники и политики», для обеспечения инвестиций и ресурсов, необходимых для изменений (BRASIL, 2010, 2011).

Решение заключается в инновациях в процессе организации системы здравоохранения, переупорядочении действий и услуг в развитии региональных сетей здравоохранения (RAS), чтобы оказать положительное влияние на показатели здоровья населения.

Пакт управления SUS устанавливает необходимость проектирования RAS, организованного на территориях регионов здравоохранения, который является привилегированным пространством для построения согласованных обязанностей и позволяет интегрировать политику и программы посредством совместных действий федерального, государственного и муниципального уровней (BRASIL, 2010).

В главе II декрета 7508/11 определяется, что SUS должна быть сфрормирована на основе региональной и иерархической сети и что еe регионы здравоохранения должны быть организованы для предоставления медицинских услуг, сфрормулированных на уровнях все большей сложности, с целью обеспечения комплексного ухода и медицинского обслуживания (BRASIL, 2001).

Пакт установил региональное пространство в качестве привилегированного места для построения согласованных обязанностей, требующих выполнения

$\mathrm{RC}: 98474$

Доступно в: https://www.nucleodoconhecimento.com.br/технология-ru/межуправленческая-комиссия 
взятых на себя обязанностей и согласованных целей, и каждая сфрера управления несет соотчетную ответственность за управление комплексом политик с четкими обязанностями (BRASIL, 2006).

Результаты наглядно показывают организацию медицинских услуг сетями медицинской помощи и федеративными соглашениями на оказание услуг, учитывающими потребности регионов здравоохранения. По мнению Santos (2017), необходимо действовать комплексно и системно, гибко разделяя компетенции, стремясь обеспечить согласие между фредеративными субъектами, которые влияют на здоровье населения, способствуя межсекторальности, способной уменьшить социальное неравенство.

\section{3 ФЕДЕРАЛИЗМ, МЕЖУПРАВЛЕНЧЕСКИЕ КОМИССИИ И ФИНАНСИРОВАНИЕ СЛУЖБ ЗДРАВООХРАНЕНИЯ}

Федерализм - это форма организации государства, которая родилась из диалектического баланса между централизацией и децентрализацией политической власти, соответствующего необходимости сохранения единства в многообразии, без концентрации власти в едином ядре и ее измельчения (DOURADO; ELIAS, 2011).

Согласно Curvina (2017), фредерализм возник в 1787 году, с Конституцией Соединенных Штатов Америки. По мнению автора, модель американского фредерализма была скопирована другими странами, сходясь, полностью или частично, к двойственности компетенций, характеризующейся сосуществованием как минимум двух конституционных сфрер автономной власти, действующих на одной территории и одного населения (MENICUCCI, 2019).

В Бразилии федерализм начался С существования единицы С централизованной властью, распределяя ее между несколькими единицами

$\mathrm{RC}: 98474$

Доступно в: https://www.nucleodoconhecimento.com.br/технология-ru/межуправленческая-комиссия 
(федеративными образованиями), не устраняя центральную власть. Эти полномочия, делегированные штатам и муниципалитетам, конституционно закреплены в фредеральном, государственном и муниципальном законодательстве. Система кооперативного федерализма, как по экономическим, социальным и культурным вопросам, через программы и совместное фринансирование, рассмотренная Viana et al (2008). «институциональная гибкость», стремление к межправительственному сотрудничеству для достижения общих целей.

Barata (2004) следует отметить, что в фредеративной организации отсутствует иерархия, поскольку каждая сфрера власти соответствует определенной компетенции, предполагая автономию федеративных образований. Хотя изучение федерализма проходит через изучение специфики каждой федерации, существуют общие характеристики, которые представляют собой основы фредеративного государства.

В нынешнем историческом контексте, в котором национальные государства играют преобладающую роль содействия социальному благополучию, существует необходимость во взаимном сотрудничестве между сорерами управления для достижения социальных и экономических целей, вытекающих из определения того, что выполнение определенных общественных функций не может быть исключительным или гегемонистским присвоением любого из федеративных образований, разделение компетенции, сотрудничества и общих интересов. Это преобладающая модель в настоящее время, называемая кооперативным федерализмом (CURVINA, 2017).

Фактически, управление государственной политикой является основополагающим для разработки целей и действий в социальноэкономической сорере, направленных на коллективное благосостояние населения, посредством сотрудничества в трех сорерах управления через построение процессов принятия решений и планирования (SOARES, 2018). Эти

$\mathrm{RC}: 98474$

Доступно в: https://www.nucleodoconhecimento.com.br/технология-ru/межуправленческая-комиссия 
процессы представляют собой «неотъемлемую дилемму между прямыми переговорами местных органов власти и стимулами, поощряемыми центральными идеатами», возникающую в связи с повторяющимися проблемами, связанными с децентрализацией и централизацией (DOURADO; ELIAS, 2011, c. 206).

Постоянной поддержкой руководства SUS является укрепление межфедеративных связей, необходимых для консолидации системы. Органический закон о здравоохранении (Закон 8.080/90) установил новые стратегии и инструменты для консолидации сетей здравоохранения, оценивая построение отношений сотрудничества между федеративными образованиями через СОАР и укрепляя координирующую роль государственных менеджеров и межуправления (BRASIL, 1990).

Фактически, децентрализация направлена на укрепление межправительственных отношений в осуществлении государственной политики и усиливает важность диалога между субнациональными правительствами и национальными правительствами при проведении политики в области здравоохранения. В дополнение к значительным изменениям в институциональной структуре в правительственной организации и в социальной сорере с акцентом на коммуникацию и разделение ответственности между федеральными субъектами в политическом и фринансовом управлении местными системами здравоохранения, расширение охвата и расширение доступа населения к медицинским услугам и действиям (MOREIRA; FERRÉ; ANDRADE, 2017).

Бесспорно, что децентрализация противоречит фринансовой и управленческой асимметрии на правительственном уровне, организации и управлению гетерогенной и неинституционально интегрированной сетью услуг, что приводит к возникновению различных местных и изолированных систем медицинских услуг, а также к фрагментации и дезорганизации услуг,

$\mathrm{RC}: 98474$

Доступно в: https://www.nucleodoconhecimento.com.br/технология-ru/меж- 
предоставляемых сообществу (LEVCOVITZ et al, 2001; SANTOS et al, 2015). Еще один важный момент, вызванный обсуждаемой авторами децентрализацией, связан с дистанцированием государственных органов, ответственных за фринансирование здравоохранения (PINAFO et al, 2020).

Взаимосвязь между децентрализацией, эффрективностью и справедливостью пронизывается сложными причинно-следственными связями, однако имеющиеся данные свидетельствуют о том, что в такой континентальной стране, как Бразилия, состоящей из пространственного разнообразия, территориального неравенства, распределения, посредничества и контроля, затраты намного перевешивают выгоды в области управления ресурсами, распределения товаров и услуг, достигнутые централизованной администрацией (AFFONSO, 1985; LIMA et al, 2015).

Фактически, географическая концентрация услуг с большей соучастием, региональные различия между населением и политико-институциональные условия фредеративных образований в Бразилии, потребность и использование имеющихся ресурсов, с разделением ответственности между сорерами управления, для согласования конфликтующих интересов различных регионов, с целью построения кооперативной и фринансовой модели в предоставлении медицинских услуг (LIMA et al, 2012).

\section{4 РУКОВОДЯЩИЕ И РЕГИОНАЛЬНЫЕ МЕЖУПРАВЛЕНИЯ - CIR:} КАНАЛ ПЕРЕГОВОРОВ И ПРИНЯТИЯ РЕШЕНИЙ МЕЖДУ МУНИЦИПАЛЬНЫМИ РУКОВОДИТЕЛЯМИ И ГОСУДАРСТВОМ В РЕГИОНЕ ЗДРАВООХРАНЕНИЯ

CIR/AL были созданы 22 августа 2011 года, и их правила определяют их как привилегированные случаи переговоров, артикуляции, предложения и соглашения относительно оперативных аспектов SUS в регионе

$\mathrm{RC}: 98474$

Доступно в: https://www.nucleodoconhecimento.com.br/технология-ru/меж- 
здравоохранения, соблюдая определения Двухсторонней межведомственной комиссии (CIB), представляя собой постоянное пространство для солидарности и совместного управления на региональном уровне, от выявления сети организованных, интегрированных и резолютивных медицинских услуг, обеспечивающих совершенствование и применение принципов SUS (COSEMS/AL, 2014).

В состав муниципальных секретарей здравоохранения и представителей государственного секретаря по вопросам здравоохранения, который имеет прерогативу координировать процесс согласования, их решения принимаются консенсусом в соответствии с положениями, установленными Пактом о здравоохранении.

В штате Алагоас путем утверждения Генерального плана регионализации (PDR) санитарный территориальный проект был пересмотрен, реорганизован в два макрорегиона здравоохранения, разделенных на десять санитарных районов, 06 (шесть) в 1-м макрорегионе, базирующемся в Масейо, и 04 (четыре) во 2-м макрорегионе со штаб-квартирой в муниципалитете Арапирака.

С миссией управления Региональной политикой в области здравоохранения, основанной на знании эпидемиологической и социально-экономической реальности муниципалитета, территории и региона, CIR координирует строительство RAR, обеспечивая доступ населения к медицинским услугам, регулируя, мониторинг и оценивая цели, установленные для муниципалитетов.

Стремясь углубить кооперативный характер межправительственных отношений, установленных Пактом о здравоохранении, и институционализировать, в рамках управления SUS, набор инструментов управления и ухода, Указ 7.508/2011 дает определение регионов здравоохранения и сетей здравоохранения, создает карту здравоохранения, Национальный перечень действий и услуг в области здравоохранения -

$\mathrm{RC}: 98474$

Доступно в: https://www.nucleodoconhecimento.com.br/технология-ru/меж- 
RENASES Национальный список основных лекарственных средств - RENAME, и COAP (BRASIL, 2011). Он создает переговорные и межправительственные артикуляционные органы, которые действуют в различных территориальных масштабах (национальном, государственном и региональном).

Согласно теории Хабермасяна, для эфффективности воспринимаемых требований в публичной сфере необходимы коммуникационные и диалоговые потоки, то есть совещательная модель демократии. В республиканской концепции общественно-политическое пространство и гражданское общество, как его инфраструктура, являются стратегическими точками демократической и коммуникативной организации. Имея фрункцию обеспечения интегративной силы и демократической автономии практики взаимопонимания между субъектами (HABERMAS, 1995).

В стратегических условиях индивиды принимают решения, предвосхищают последствия своих действий, выбирают политические институты, словом, действуют политически. И то, как они действуют, играет решающую роль в получении и поддержании демократии, чтобы открыть пути, которые позволяют общаться, способствуя большему благу, праву на здоровье.

Habermas (1995) с точки зрения дискурсивной теории, демократическое формирование воли узаконивается через принятие решений и коммуникативные предположения, которые позволяют через рациональность использовать разум для диалога с потребностями здоровья населения с целью гарантировать справедливые и кооперативные процессы.

Хорошее развитие сотрудничества происходило через CIR, способствует формулированию и регулированию действий на территориях посредством совместных переговоров, предпринятых федеративными образованиями в солидарной перспективе (Lima, 2012; Santos et al., 2014). Таким образом, укрепление стратегического руководства в регионе здравоохранения может

$\mathrm{RC}: 98474$

Доступно в: https://www.nucleodoconhecimento.com.br/технология-ru/меж- 
свести воедино то, что сама децентрализация фрагментировала и преодолеть проблемы организованной интеграции медицинской помощи в регионах здравоохранения (LIMA et al, 2016).

Carvalho et al (1995) считают, что в зависимости от того, что было установлено в Федеральной конституции, муниципалитеты пользуются политической и административной автономией в планировании и управлении своими местными системами здравоохранения. Поэтому единственным способом вмешательства министерства и государственных секретариатов здравоохранения в муниципальное управление были бы соглашения и контракты, свободно устанавливаемые между сторонами.

По словам Noronha et al (2008), SUS «является частью широкой концепции права на здоровье и роли государства в гарантировании этого права, включая в свою институциональную и директивные структуры, пространства и инструменты для демократизации и совместного управления системой здравоохранения».

Учитывая эти характеристики и фредеративную модель, определенную конституционно в здравоохранении, укрепление совместного управления и инструментов, которые могут способствовать ему, среди них особенно важно.

Исследование позволило достичь нескольких соображений по этой теме, не намереваясь исчерпать ее, учитывая ограничения, налагаемые вырезанным исследованием или даже типом анализа, предложенного исследованием.

\section{5. ЗАКЛЮЧЕНИЕ}

Обеспечение доступа к медицинским услугам, обращение за комплексной медицинской помощью требует системной организации, исходящей из пактов о сотрудничестве в рамках фредеративного управления, направленных на укрепление организации регионов здравоохранения. Наличие CIR в качестве

$\mathrm{RC}: 98474$

Доступно в: https://www.nucleodoconhecimento.com.br/технология-ru/меж- 
важного органа в координации, организации и строительстве пространств соглашения с целью реконструкции и социальной организации.

Институциональное обучение, являющийся результатом динамики участия в CIR, укрепляет межведомственное управление и представляет собой важный компонент для построения региональной сети.

Это исследование показывает, что региональное всеобъемлющее планирование, организация действий и услуг, финансирование и региональное управление являются важнейшими элементами процесса регионализации, достигаемого в ходе обсуждений в CIR, a также других вопросов, согласованных на совещаниях, как это описано в резолюциях, с уделением основного внимания предоставлению медицинских услуг, доступных для населения.

Сотрудничество, как правило, благоприятствует муниципалитетам, которые являются частью региона, поскольку оно позволяет оптимизировать ресурсы, солидарное использование средств, распределенных между федеративными субъектами, и гарантировать прибыльность для муниципалитетов, способных участвовать, оставляя ясно, что CIR/ AL являются подлинным локальным пространством соглашения и межфедеративной артикуляции.

\section{ИСПОЛЬЗОВАННАЯ ЛИТЕРАТУРА}

AFFONSO, Rui de Brito Álvarez. SILVA, Pedro Luiz Barros. (Org). A federação em perspectiva: ensaios selecionados. São Paulo 10 (3) Edições Fundap; 1995 [acesso em 3 jul 2020]. Disponível em:https://www.seade.gov.br/wpcontent/uploads/2014/07/v10n3.pdf

ANDRADE, Laurielle de Souza.; FRANCISCHETTI, leda. Referência e contrarreferência compreensões e práticas. Sal. \& Transf. Soc. Florianópolis, v. 10, n. 1/2/3, p. 54-63. 2019 [acesso em 13 jul. 2021]. Disponível em:

$\mathrm{RC}: 98474$

Доступно в: https://www.nucleodoconhecimento.com.br/технология-ru/меж- 
file://C:/Users/nadja/Dropbox/My\%20PC\%20(LAPTOP-

EA4SVGFV)/Downloads/5281-22616-1-PB.pdf.

BARATA, Luiz Roberto Barradas. TANAKA, Oswaldo Yoshimi. MENDES, José Dínio Vaz. Por um processo de descentralização que consolide os princípios do Sistema Único de Saúde. Epidemiologia e Serviços de Saúde, Brasília, 13 (1) 1524. 2004 [acesso em 02 jun 2020]. Disponível em: http://scielo.iec.gov.br/pdf/ess/v13n1/v13n1a03.pdf

BRASIL. Conselho Nacional de Secretários de Saúde. Legislação Estruturante do SUS/CONASS. Brasília, 2011. 534. [acesso em 25 jul, 2020]. Disponível em: http://bvsms.saude.gov.br/bvs/publicacoes/para_entender_gestao_sus_v13.pdf

BRASIL. Constituição (1988). Constituição da República Federativa do Brasil. promulgada em 5 de outubro de 1988. Brasília, DF: Senado Federal;1988 [acesso em 10 mai 2020]. Disponível em: https://www2.senado.leg.br/bdsf/bitstream/handle/id/518231/CF88_Livro_EC91_201 6.pdf

BRASIL. Decreto n. 7.508, de 28 de junho de 2011. Regulamenta a Lei n. 8.080, de 19 de setembro de 1990, para dispor sobre a organização do Sistema único de Saúde - SUS, o planejamento da saúde, a assistência à saúde e a articulação interfederativa, e dá outras providencias. Diário Oficial da União, Poder Executivo, Brasília, DF, 29 jun. 2011. Seção 1, p 1. [acesso em 10 fev 2020]. Disponível em http://www.planalto.gov.br/ccivil_03/_Ato2011-2014/2011/Decreto/D7508.htm.

BRASIL. Lei o 8.080, de 19 de setembro de 1990. Lei Orgânica da Saúde. Dispõe sobre as condições para a promoção, proteção e recuperação da saúde, a organização e o funcionamento dos serviços correspondentes e dá outras providências. Brasília, set. 1990. [acesso em 23 abri 2020]. Disponível em: http://www.planalto.gov.br/ccivil_03/leis//8080.htm

RC: 98474

Доступно в: https://www.nucleodoconhecimento.com.br/технология-ru/межуправленческая-комиссия 
BRASIL. Ministério da Saúde. Portaria 4.279, de 30 de dezembro de 2010. Estabelece diretrizes para a organização da Rede de Atenção à Saúde no âmbito do Sistema Único de Saúde (SUS). Diário Oficial da União 31 dez. 2011[acesso em 27 jul 2020].

Disponível

em:

https://bvsms.saude.gov.br/bvs/saudelegis/gm/2010/prt4279_30_12_2010.html

BRASIL. Ministério da Saúde. Secretaria de Atenção à Saúde. Departamento de Regulação, Avaliação e Controle de Sistemas. Diretrizes para a programação pactuada e integrada da assistência à saúde. Brasília. 2006. [acesso em: 27 jul 2020].

Disponível

em: http://bvsms.saude.gov.br/bvs/publicacoes/DiretrizesProgPactuadalntegAssistSaude. pdf

BRASIL. Ministério da Saúde. Secretaria de Gestão e Participativa. Contrato Organizativo da Ação Pública da Saúde. Brasília. 2011 [cesso 30 jul 2020]. Disponível em: http://bvsms.saude.gov.br/bvs/publicacoes/contrato_organizativo_acao_publica_sau de.pdf

BRASIL. Resolução oo 1 setembro de 2011. Gabinete do Ministério da Saúde. Comissão Intergestores Tripartite. Brasília, [citado 07 Jul. 2020]. Disponível em: https://bvsms.saude.gov.br/bvs/saudelegis/cit/2011/res0001_29_09_2011.html

CARVALHO, Guido Ivan. SANTOS, Lenir. Comentários à lei orgânica da saúde: sistema único de saúde. São Paulo: Ed. Hucitec, 1995

CONSELHO DE SECRETÁRIOS MUNICIPAIS DE ALAGOAS. O papel dos gestores de saúde nas comissões Intergestores regionais. Maceió, 2014 [acesso em 12 abr 2020]. Disponível em: http://www.cosemsal.org/old/public/documentos/manual-azul-o-papel-dos-gestoresde-saude.pdf

RC: 98474

Доступно в: https://www.nucleodoconhecimento.com.br/технология-ru/межуправленческая-комиссия 
CURVINA, Ana Cristina Carvalho. A regionalização da saúde no federalismo brasileiro. Cad. Ibero-Amer. Dir. Sanit., Brasília, 6(2):42-57, abr./jun, 2017. [acesso em 13 fev 2020]. Disponível em: http://dx.doi.org/10.17566/ciads.v6i2.385

DOURADO, Daniel de Araújo.; ELIAS, Paulo Eduardo Mangeon. Regionalização e dinâmica política do federalismo sanitário brasileiro. Rev. Saúde Pública. São Paulo, v. 45, n. 1, p. 204-11. 2011. [acesso em 05 jul. 2021]. Disponível em: https://www.scielo.br/j/rsp/a/bCWB3sWTXQLXWjjFkcWwgLt/?format=pdf\&lang=pt

DUARTE, Ligia Schiavon.; MENDES, Áquilas Nogueira.; LOUVISONA, Marília, Cristina Prado. O processo de regionalização do SUS e a autonomia municipal no uso dos recursos financeiros: uma análise do estado de São Paulo (2009-2014). Saúde Debate, Rio de Janeiro, v. 42, n. 116, p. 25-37. 2018. [acesso em 10 jul 2020].

https://www.scielo.br/j/sdeb/a/gcPyhjjWdrqZcG9V4nYhPBd/?format=pdf\&lang=pt.

HABERMAS, Jurgen. Três Modelos Normativos de Democracia. Cadernos da Escola do Legislativo, Belo Horizonte, 3 (3)105-122, jan.-jun., 1995.

LEVCOVITZ, Eduardo. LIMA, Luciana Dias de. MACHADO, Cristiane. Vieira. Política de saúde nos anos 90: relações intergovernamentais e o papel das Normas Operacionais Básica. Ciência e Saúde Coletiva, Rio de Janeiro, 6, (2) 269-291, 2001 [acesso em 10 jul 2020]. Disponível em: https://www.scielo.br/pdf/csc/v6n2/7003.pdf.

LIMA, Luciana Dias de. et al. Regionalização e acesso à saúde nos estados brasileiros: condicionantes históricos e político-institucionais. Ciência e Saúde Coletiva, Rio de Janeiro, 17 (11) 2881-2892, 2012 [acesso 10 jun 2020]. Disponível em: https://www.scielo.br/pdf/csc/v17n11/v17n11a04.pdf

LIMA, Luciana Dias de.; ALBUQUERQUE, Mariana Vercesi.; SCATENA, João Henrique Gurtler. Quem governa e como se governam as regiões e redes de

$\mathrm{RC}: 98474$

Доступно в: https://www.nucleodoconhecimento.com.br/технология-ru/межуправленческая-комиссия 
atenção à saúde no Brasil? Contribuições para o estudo da governança regional na saúde. Novos Caminhos, n. 8. 2016. [acesso em 29 fev 2020]. Disponível: https://www.resbr.net.br/wp-content/uploads/2016/02/Novos-Caminhos-8.pdf.

LIMA, Luciana Dias de. et al. Descentralização e regionalização: dinâmica e condicionamento da implantação do pacto pela saúde no Brasil. Ciência \& Saúde Coletiva, n. 17, v. 7, p. 1903-1914, 2012. [acesso em 29 fev. 2020]. Disponível em: https://www.scielo.br/j/csc/a/FyqLwWmbv8WQs8BPW8scpTt/?lang=pt

MENICUCCI, Telma Maria Gonçalves. Regionalização no federalismo brasileiro. Cad. Saúde Pública 2019; 35 Sup 2: e00078419. [acesso em 29 fev 2020]. Disponível: https://www.scielosp.org/article/csp/2019.v35suppl2/e00078419/pt/

MINAYO, Maria Cecília de Souza. O desafio do conhecimento. Pesquisa qualitativa em saúde; $12^{a}$ ed; São Paulo. Hucitec. 2010. 407p. ISBN 978-85-271-0181-3.

MOREIRA, Laura Monteiro de.; FERRÉ, Felipe.; ANDRADE, Eli lola Gurgel. Financiamento, descentralização e regionalização: transferências federais e as redes de atenção em Minas Gerais, Brasil. Ciência \& Saúde Coletiva, n 22, v. 4, p. 1245-1256, 2017. [acesso em 21 ago 2021]. Disponível em: https://www.scielosp.org/pdf/csc/2017.v22n4/1245-1256/pt.

NORONHA, José Carvalho de. LIMA, Luciana. Dias de. MACHADO, Cristiane Vieira. O Sistema Único de Saúde: SUS. In: Giovanella L. et al. (Org.). Políticas e sistemas de saúde no Brasil. Rio de Janeiro: Fiocruz, 2008. p. 365-394.

PINAFO, Elisangela. et al. Problemas e estratégias de gestão do SUS: a vulnerabilidade dos municípios de pequeno porte. Ciência \& Saúde Coletiva, n2. 25, v. 5, p. 1619-1628, 2020 [acesso em 21 ago 2021]. Disponível em: https://scielosp.org/pdf/csc/2020.v25n5/1619-1628/pt

RC: 98474

Доступно в: https://www.nucleodoconhecimento.com.br/технология-ru/межуправленческая-комиссия 
SANTOS, Adriano Maia dos. GIOVANELLA, Ligia. Governança regional: estratégias e disputas para gestão em saúde. Revista de Saúde Pública, São Paulo, 48 (4) 622-631, 2014[acesso em 10 jun 2020]. Disponível em: https://www.resbr.net.br/wpcontent/uploads/historico/governan\%C3\%A7a_regional.pdf

SANTOS, Lenir. CAMPOS, Gastão Wagner de Souza. SUS Brasil: a região de saúde como caminho saúde e Sociedade, São Paulo, 24 (2) 438-446, 2015 [acesso em 10 jul 2020]. Disponível em: https://www.scielo.br/pdf/sausoc/v24n2/0104-1290-sausoc-24-02-00438.pdf

SANTOS, Lenir. Região de saúde e suas redes de atenção: modelo organizativosistêmico do SUS. Ciência \& Saúde Coletiva, 22(4):1281-1289, 2017. [acesso em 29 jul, 2020]. Disponível em: https://www.scielosp.org/pdf/csc/2017.v22n4/1281$1289 / \mathrm{pt}$

SOARES, Marcia Miranda. MACHADO, José Ângelo. Federalismo e políticas públicas. Brasília: Enap, 2018. 112. [acesso em: 29 fev 2020]. ISBN: 978-85-2560081-3Disponível

em: https://repositorio.enap.gov.br/bitstream/1/3331/1/Livro_Federalismo\%20e\%20Pol\% C3\%ADticas\%20P\%C3\%BAblicas.pdf.

VIANA, Ana Luiza D'Ávila. LIMA, Luciana Dias. OLIVEIRA, Roberta. Gondim de. Descentralização e federalismo: a política de saúde em novo contexto - lições do caso brasileiro. Ciência e Saúde coletiva. 2002 Jul; 7 (3):493-507. [acesso em 5 mai 2020]. Disponível em: https://www.scielo.br/pdf/csc/v7n3/13027.pdf

VIANA, Ana Luiza D' Ávila. et al. Novas Perspectivas para a regionalização da saúde; São Paulo em perspectiva, 22 (1) 92-106, jan/jun.2008 [acesso em 7 jun 2020].

Disponível

em:

http://produtos.seade.gov.br/produtos/spp/v22n01/v22n01_07.pdf

RC: 98474

Доступно в: https://www.nucleodoconhecimento.com.br/технология-ru/меж-

управленческая-комиссия 
WAGNER, Gastão. Efeitos paradoxais da descentralização do Sistema Único de Saúde do Brasil; In: Fleury S. (Org.). Democracia, descentralização e desenvolvimento: Brasil e Espanha. Rio de Janeiro: FGV, 2006. 417-442. Disponível em https://www.scielo.br/pdf/csc/v17n11/v17n11a04.pdf.

Опубликовано: Март 2021 г.

Утверждено: Сентябрь 2021 г.

RC: 98474

Доступно в: https://www.nucleodoconhecimento.com.br/технология-ru/меж- 